\title{
Uma Análise Qualitativa sobre Atividades Remotas em Disciplinas no Período de Isolamento Social
}

\author{
Clemilson Costa dos Santos $^{1}$, Gabriel A. L. Paillard ${ }^{1}$, Leonardo O. Moreira ${ }^{1}$ \\ Francisco Romes da Silva Filho ${ }^{2}$, Emanuel F. Coutinho ${ }^{2}$ \\ ${ }^{1}$ Instituto Universidade Virtual (IUVI) \\ Universidade Federal do Ceará (UFC) - Fortaleza - CE - Brasil \\ ${ }^{2}$ Universidade Federal do Ceará (UFC) - Quixadá - CE - Brasil \\ \{clemilson.santos, gabriel, leoomoreira\}evirtual.ufc.br, \\ romes221begmail.com, emanuel.coutinhodufc.br
}

\begin{abstract}
With the Coronavirus pandemic, several consequences have emerged for education in general. Due to actions of social distance and prevention, faceto-face access to classrooms, laboratories and departments was impaired, motivating the continuity of academic activities remotely. For this, infrastructure and activities had to be adequate. The objective of this work is to carry out a qualitative analysis with Grounded Theory on the application of remote activities in disciplines during the period of social isolation. For their assistance, a questionnaire was applied to professors who were teaching subjects in the remote mode. As a result, it is clear that adequate infrastructure is essential for communication to flow well, and the digital inclusion of students is a concern.

Resumo. Com a pandemia do Coronavírus, diversas consequências surgiram para o ensino de maneira geral. Devido a ações de distanciamento social e de prevenção, o acesso presencial a salas de aula, laboratórios e secretarias ficou prejudicado, motivando a continuidade das atividades acadêmicas de maneira remota. Para isso, infraestrutura e atividades tiveram que ser adequadas. $O$ objetivo deste trabalho é realizar uma análise qualitativa com Grounded Theory sobre a aplicação de atividades remotas em disciplinas no período de isolamento social. Para seu atendimento, um questionário foi aplicado a docentes que estavam lecionando disciplinas na modalidade remota. Como resultados, tem-se que infraestrutura adequada é essencial para que a comunicação possa fluir bem, e a inclusão digital dos alunos é uma preocupação.
\end{abstract}

\section{Introdução}

Na cidade chinesa de Wuhan, no final do ano de 2019, registraram-se os primeiros casos acometidos pelo COVID-19 e se alastrou, rapidamente, por outras províncias chinesas [Li et al. 2020] até se tornar um causador de uma pandemia mundial. COVID-19 foi o identificador dado pela Organização Mundial de Saúde $(\mathrm{OMS})^{1}$ para a doença causada pelo vírus SARS-CoV-2 [Moreira Neto et al. 2020]. O vírus SARS-CoV-2, mais conhecido popularmente como novo coronavírus, possui um alto grau de contágio e propagação por meio de secreções e excreções respiratórias.

\footnotetext{
${ }^{1}$ WHO - World Health Organization. Disponível em $<$ https://www.who.int/ > Acesso em: 10 de julho de 2020.
} 
Devido ao alto grau de contágio e propagação do SARS-CoV-2, o isolamento social tem sido a ação preventiva e defendida pela OMS, sendo uma das abordagens principais de combate à disseminação do vírus SARS-CoV-2 [Silva Junior et al. 2020]. Além disso, a população, no intuito de aumentar o grau de prevenção contra este vírus, está colocando em prática medidas de higienização de objetos e de proteção pessoal nas áreas mais vulneráveis do corpo que são: boca, nariz e olhos.

No âmbito universitário, diante do acontecimento pandêmico e das medidas preventivas de isolamento social, houve uma interrupção das atividades presenciais na grande maioria das Instituições Públicas de Ensino Superior [Silva Junior et al. 2020]. Como consequência, o Ministério da Educação do Brasil possibilitou, em caráter excepcional, que instituições de educação no ensino superior realizassem atividades remotas em disciplinas presenciais por meio das Tecnologias da Informação e Comunicação (TICs) enquanto durar a pandemia causada pelo vírus SARS-CoV-2 [DOU 2020].

Neste contexto e para atividades remotas, muitos cursos de graduação necessitaram de infraestrutura adequada para a plena execução das aulas e gestão. Muitos cursos presenciais, como àqueles ligados à área tecnológica, que necessitam de uma infraestrutura para que os discentes possam utilizar equipamentos ou ambientes para uma melhor qualidade de ensino, aprendizagem e avaliação, sofreram um impacto [Santos et al. 2020]. Como exemplo de uma parte dessa infraestrutura, pode-se comentar sobre os laboratórios de informática que possuem computadores com recursos computacionais adequados, softwares e periféricos que são essenciais para a qualidade e atualidade de algumas disciplinas do curso.

No cenário atual de pandemia e isolamento social como forma de evitar a disseminação do vírus SARS-CoV-2, a necessidade por uma infraestrutura que possibilite a realização das atividades de ensino de maneira remota se torna essencial. E junto a essa necessidade, diversas preocupações, dificuldades e consequências surgem.

A plena utilização das tecnologias digitais merece uma atenção especial, pois é muito fácil que os docentes e discentes se desmotivem, que não possuam a infraestrutura adequada para a execução das atividades, e não tenham a prática, ritmo e disciplina necessários. Diante destas situações e cenários, acredita-se que alguns prejuízos podem ser ocasionados no processo de ensino e aprendizagem em algumas disciplinas, se adotarem atividades remotas, devido a sua natureza pedagógica ou metodológica.

O objetivo geral deste artigo é realizar uma análise qualitativa sobre a aplicação de atividades remotas em disciplinas no período de isolamento social em um curso de graduação presencial. Para seu atendimento, um questionário foi aplicado a docentes que estavam lecionando disciplinas na modalidade remota. Para a análise dos dados, utilizouse Grounded Theory.

Este artigo está organizado da seguinte forma: A Seção 2 apresenta alguns trabalhos relacionados à proposta deste trabalho. A Seção 3 apresenta a metodologia e suas etapas que foram definidas para guiar o presente trabalho. Os resultados e análises obtidos são apresentados, discutidos e comentados na Seção 4. Por fim, a Seção 5 comenta as considerações finais identificadas neste trabalho e apresenta os trabalhos futuros. 
IX Congresso Brasileiro de Informática na Educação (CBIE 2020)

Anais do XXXI Simpósio Brasileiro de Informática na Educação (SBIE 2020)

\section{Trabalhos Relacionados}

Silva Junior et al. (2020) apresentaram uma análise qualitativa descritiva de dados levantados sobre as atividades na pós-graduação por meio da utilização de ferramentas digitais diante da pandemia do novo coronavírus. Para isso, um questionário foi aplicado junto ao corpo docente e discente dos cursos de pós-graduação de uma Instituição de Ensino Superior. Diante dos resultados obtidos, observou-se que as aulas dos cursos de pós-graduação strictu sensu poderiam ser retomadas por meio das tecnologias disponíveis. Ademais, é destacado no estudo que seja assegurado aos discentes que não possuem os meios de acompanharem as disciplinas, a oferta das disciplinas dentro do limite temporal do curso.

Cursos ofertados na modalidade de Educação a Distância (EAD) requerem dedicação, comprometimento e disciplina dos alunos [Gonçalves et al. 2018]. As interações dos alunos em ambientes virtuais de aprendizagem podem ser um indicador do seu aprendizado. Alguns trabalhos na literatura procuraram analisar o desempenho dos alunos em cursos à distância, em diferentes ambientes. Gonçalves et al. (2018) investigaram notas e interações de alunos, além de interações de tutores no a ambiente virtual de aprendizagem Moodle, identificando correlação entre interações e notas dos alunos, com uma ferramenta construída e disponibilizada para a comunidade. Cavalcanti et al. (2018) identificaram variáveis que melhor descrevem os comportamentos dos alunos no ambiente e quanto eles influenciam em seu desempenho, sendo diretamente relacionado ao número de interações no ambiente, sendo a capacidade de gerenciar o tempo em que ele se envolve em atividades acadêmicas e a capacidade de estabelecer seus objetivos nas atividades mais críticas para a sua aprendizagem.

Os problemas no ensino da computação pela educação a distância podem resultar das características de discentes, docentes, instituição, meio utilizado para disseminar material e área da computação. Jones (1996) examinou alguns problemas enfrentados na oferta de computação à distância, descrevendo algumas das soluções implementadas e problemas gerados por essas soluções. A experiência demonstrou que o uso apropriado da tecnologia, incluindo computadores, software, ferramentas de aprendizado assistido por computador, comunicação mediada por computador, correio de voz, áudio e vídeo, pode contribuir com soluções para muitos dos problemas da educação à distância.

Um recurso didático de valor na Educação a Distância é a videoaula, podendo ser informativa, lúdica e motivadora da aprendizagem [Mogetti et al. 2020]. Mogetti et al. (2020) relataram a percepção dos professores formadores sobre o uso de videoaulas interativas como recurso de ensino, e como elas estão sendo produzidas e de que maneira estão sendo utilizadas como recurso de ensino. A investigação foi feita por meio de um questionário elaborado com questões abertas e fechadas e como resultado, os professores mostraram-se frágeis diante da falta de capacitação oferecida para esse novo modo de ensinar, assim como apontaram a falta de uma equipe de apoio para seu trabalho. Porém se dispuseram para a atualização dos seus conhecimentos e relataram sua experiências.

Todos os trabalhos relacionados se assemelham a esta proposta na intenção de relatar experiências sobre o uso de tecnologias para o ensino remoto, análises de desempenho, utilização de infraestruturas ou ferramentas, suas dificuldades e relações para os alunos, para a aprendizagem e sobre o ambiente. 
IX Congresso Brasileiro de Informática na Educação (CBIE 2020)

Anais do XXXI Simpósio Brasileiro de Informática na Educação (SBIE 2020)

\section{Metodologia}

O objetivo principal da pesquisa, como mencionado na introdução, é analisar qualitativamente a aplicação de aulas remotas em um curso de graduação presencial diante das medidas de prevenção contra o SARS-CoV-2. Segundo Gil (2008) pesquisas descritivas objetivam a explanação das características de fenômenos em observação, ajudando a levantar opiniões. Além disso, algumas pesquisas descritivas acabam servindo para proporcionar uma nova visão do problema [Gil 2008]. Para a fase de levantamento e coleta dos dados, utilizou-se o instrumento de questionário. O público-alvo para a aplicação do questionários foram os docentes do curso de graduação presencial.

Este trabalho faz parte de uma pesquisa maior, relatada em [Santos et al. 2020], onde um questionário bem mais amplo foi aplicado, analisando diversas questões de pesquisa. A pesquisa constou do preenchimento de um questionário com questões de múltipla escolha e abertas. No escopo deste trabalho, apenas as questões abertas sobre vantagens e desvantagens da aplicação das aulas na modalidade remota serão analisadas com Grounded Theory. Alguns resultados de algumas questões de múltipla escolha serão apresentados para descrever o perfil dos participantes.

Na coleta dos dados, por meio do questionário, levou-se em consideração apenas as turmas de disciplinas que estavam sendo ofertadas no semestre 2020.1, pois os envolvidos nas turmas do semestre 2020.1 foram impactados pelo período de isolamento social. O questionário foi composto por 12 questões, com 10 questões obrigatórias e 2 questões opcionais. As 2 questões opcionais são subjetivas e o intuito destas duas questões é obter a visão dos docentes quanto às vantagens e desvantagens em relação às atividades remotas, sendo elas: "Quais as vantagens em relação às atividades remotas?" e "Quais as desvantagens em relação às atividades remotas?”.

A análise qualitativa deste trabalho foi inspirada nos procedimentos de análise apresentados em [Ferreira et al. 2018]. Nessa análise, procedimentos da metodologia Grounded Theory [Corbin and Strauss 2014] foram aplicados. A Grounded Theory visa criar uma teoria a partir dos dados coletados e analisados sistematicamente, sendo composta por três fases: (1) codificação aberta, (2) codificação axial e (3) codificação seletiva. Na codificação aberta, se executa uma quebra, análise, comparação, conceituação e categorização dos dados. Na codificação axial, associam-se as categorias às suas subcategorias, formando categorias mais relacionadas e densas. Por fim, na codificação seletiva, se identifica a categoria ou ideia central do estudo, correspondente à teoria na qual todas as categorias estão relacionadas. Strauss e Corbin explicam que o pesquisador pode utilizar apenas alguns passos para atingir seu objetivo de pesquisa [Corbin and Strauss 2014]. Então, nessa pesquisa, apenas as fases 1 e 2 da Grounded Theory foram utilizadas para a identificação das categorias e suas relações. Adicionalmente, para evitar tendências nas análises, outro pesquisador revisou o resultado.

\section{Resultados e Análises}

O questionário foi aplicado no semestre 2020.1, com docentes do curso de graduação presencial Sistemas e Mídias Digitais da Universidade Federal do Ceará. O curso de graduação analisado possui disciplinas das áreas de Tecnologias Digitais. No total houveram 36 respostas, onde cada resposta descreve a visão do docente sobre o contexto de uma determinada disciplina e impactos sobre os discentes. Das 36 respostas, 12 disciplinas fa- 
ziam parte da área de Sistemas Multimídia, 8 disciplinas da área de Mídias Digitais e 16 disciplinas que são gerais ou particulares do próprio curso. Disciplinas como introdução ao curso, trabalho de conclusão do curso e metodologia da pesquisa científica são disciplinas consideradas particulares ou gerais.

Uma questão analisada é em relação ao que o docente utiliza como parte do conteúdo em suas disciplinas, como material didático, equipamentos ou ferramentas. A maioria dos docentes indicou que utiliza slides nas aulas, Muitas menções de uso de ferramentas computacionais para modelagem, dispositivos eletrônicos (câmeras, tablets etc.), fóruns, chats e redes sociais. Ainda assim, 22 docentes informaram que utilizam livros, o que seria uma dificuldade nesse momento de inacessibilidade de bibliotecas físicas. Alguns docentes expuseram que utilizam metodologias para observação em loco, onde necessita que o discente esteja no modo presencial. O curso possui características práticas, e pelos resultados percebeu-se a utilização de equipamentos e meios digitais são conteúdos predominantes no curso. Para consumir muitos destes conteúdos, conectividade com a internet e infraestrutura são essenciais.

Outra questão interessante foi sobre como a avaliação é realizada nas disciplinas pelos docentes. A maioria dos docentes destacou trabalhos práticos. Uma quantidade razoável de respostas dos docentes indicou utilizarem provas escritas. Poucas menções sobre provas online e avaliação por meio de mensagens de chat, fóruns e redes sociais. Percebe-se que os docentes podem ter dificuldades nas atividades remotas, pois a maioria adota como forma de avaliação trabalhos práticos. Isso implica na necessidade de uma infraestrutura mínima para a plena realização destes trabalhos por parte dos discentes.

\subsection{Analise Qualitativa}

Durante a análise qualitativa, 11 categorias foram identificadas, com a seguinte frequência de citações em ordem decrescente: Infraestrutura (13), Comunicação (11), Inclusão (11), Organização (10), Tempo (9), Aulas (8), Autonomia (6), Orientação (5), Fator Psicológico (2), Gestão Acadêmica (2) e Ociosidade (2). A Tabela 1 exibe as descrição de cada categoria. Doze relacionamentos entre categorias foram identificados. A Figura 1 exibe as categorias associadas às vantagens e suas relações. A Figura 2 exibe as categorias associadas às desvantagens e suas relações.

A associação entre Aula e Comunicação é um aspecto destacado na pesquisa, como reforçado por $\mathbf{P 2 6}$ com "Eu estou ministrando remotamente atividades de programação. Os alunos me relataram que tem sido bom, uma oportunidade de conversar com outros e aprender algo novo.".

A autonomia foi citada em alguns comentários, como no de $\mathbf{P 3 1}$ em "Flexibilidade de horário para interação com o curso, maior desenvolvimento de autonomia no processo de aprendizagem e força o professor a ser mais um orientador sobre os assuntos que são abordados do que um transmissor de conhecimento". Comunicação se relacionou com Orientação, como no comentário de $\mathbf{P 2 5}$ com "É preciso uma interação mais efetiva com o discente, para o progresso na orientação. Além disso, o processo é bem mais rápido presencialmente e não exige recursos de conectividade para uma eventual videoconferência.".

A questão da inclusão, principalmente a digital, foi reforçado em vários comentários, como a preocupação de $\mathbf{P 2 4}$ em "A impossibilidade de garantir que o conteúdo 
IX Congresso Brasileiro de Informática na Educação (CBIE 2020)

Anais do XXXI Simpósio Brasileiro de Informática na Educação (SBIE 2020)

Tabela 1. Descrição das categorias identificadas na análise qualitativa

\begin{tabular}{|c|c|}
\hline Categoria & Descrição \\
\hline Aulas & $\begin{array}{l}\text { Exposição e transmissão de conhecimento realizada por um professor. Dentro do } \\
\text { contexto é especificado como a oportunidade de continuar a expor conhecimento } \\
\text { em um ambiente remoto. }\end{array}$ \\
\hline Autonomia & $\begin{array}{l}\text { Capacidade de raciocinar e tomar decisões independentes. Portanto, a partir de } \\
\text { orientações no ambiente remoto os processos na busca pela aprendizagem do in- } \\
\text { divíduo são definidos pelo próprio. }\end{array}$ \\
\hline Comunicação & $\begin{array}{l}\text { Ação de troca de informações entre indivíduos. Processo de grande importância } \\
\text { para a realização de atividades remotas, para o seu acompanhamento, para } \\
\text { atualizações, para apresentar dúvidas e explicá-las. }\end{array}$ \\
\hline Fator Psicológico & $\begin{array}{l}\text { O estado mental do ser humano impacta em qualquer atividade que ele venha a } \\
\text { realizar, independente da sua natureza. Consequentemente, a participação de aulas } \\
\text { de maneira remota é afetada, principalmente, considerando o contexto presente. } \\
\text { São também sentimentos que o aluno possa ter devido ao impacto da pandemia. }\end{array}$ \\
\hline Gestão Acadêmica & $\begin{array}{l}\text { Administração e controle dos diferentes elementos presentes em uma determinada } \\
\text { instituição. Por exemplo, o gerenciamento do calendário acadêmico. }\end{array}$ \\
\hline Inclusão & $\begin{array}{l}\text { Socialmente. É a ação que almeja igualdade entre indivíduos em determinado con- } \\
\text { texto. Portanto, possibilita a integração e participação de todos em um ambiente. } \\
\text { Dentro do contexto, representa a participação dos alunos de forma igualitária. }\end{array}$ \\
\hline Infraestrutura & $\begin{array}{l}\text { Infraestrutura é a base, uma sustentação para algo, seja equipamentos, serviços, } \\
\text { sistemas, materiais, softwares etc. Na situação apresenta-se como meio para } \\
\text { o acesso às aulas remotas, meio esse que se dá com a internet, sistemas de } \\
\text { comunicação, dispositivo eletrônico e outros. Vale ressaltar também que a quali- } \\
\text { dade da infraestrutura é de suma importância. Também se inclui material utilizado } \\
\text { para a transmissão de conhecimento em aulas. }\end{array}$ \\
\hline Ociosidade & Inatividade. Tempo sem realização de atividades, precisamente e tempo livre. \\
\hline Organização & $\begin{array}{l}\text { Ordenação de todos os elementos presentes. Em ambientes com muitas variáveis } \\
\text { presentes, apresenta-se como necessária para o atendimento de um objetivo. }\end{array}$ \\
\hline Orientação & $\begin{array}{l}\text { A orientação é a ação e o efeito de orientar. No ambiente estudantil, tem-se como } \\
\text { muito importante instruções constantes aos alunos, para realização do objetivo que } \\
\text { é o aprendizado. }\end{array}$ \\
\hline Tempo & $\begin{array}{l}\text { Tempo relativo ao período dedicado para realizar atividades. Considera-se mais } \\
\text { tempo livre, devido às circunstâncias, gerando um aproveitamento diferente para } \\
\text { o mesmo. }\end{array}$ \\
\hline
\end{tabular}

e as experiências sejam distribuídas de modo equânime entre alunos" e em relação às aulas, como na menção de $\mathbf{P 2 6}$ com "Alguns alunos relataram que não tem ambiente propício em casa para aulas. Moram em casas pequenas com muita gente. Então as atividades que tenho feito são opcionais.”.

A infraestrutura se relaciona com várias categorias: aula, comunicação, inclusão e tempo. Esta foi a categoria mais referenciada no discurso do respondentes. Exemplos de citações incluem associações com Tempo, como a menção de $\mathbf{P 3 3}$ com "O aluno poder realizar as atividades em um horário que lhe seja mais propício (assumindo um caso de um aluno que disponha de conexão com Internet, equipamento adequado e ambiente adequado em casa)." e o relato de $\mathbf{P 1 4}$ como causa de inclusão em "Nem todos os alunos conseguem acessar a internet facilmente o que compromete a aprendizagem; os trabalhos em grupo são mais complexos e exige mais do que uma simples conexão com a internet, mas uma conexão remota entre todos os participantes que ainda não desenvolveram uma cultura para trabalhar de forma totalmente remota.". 


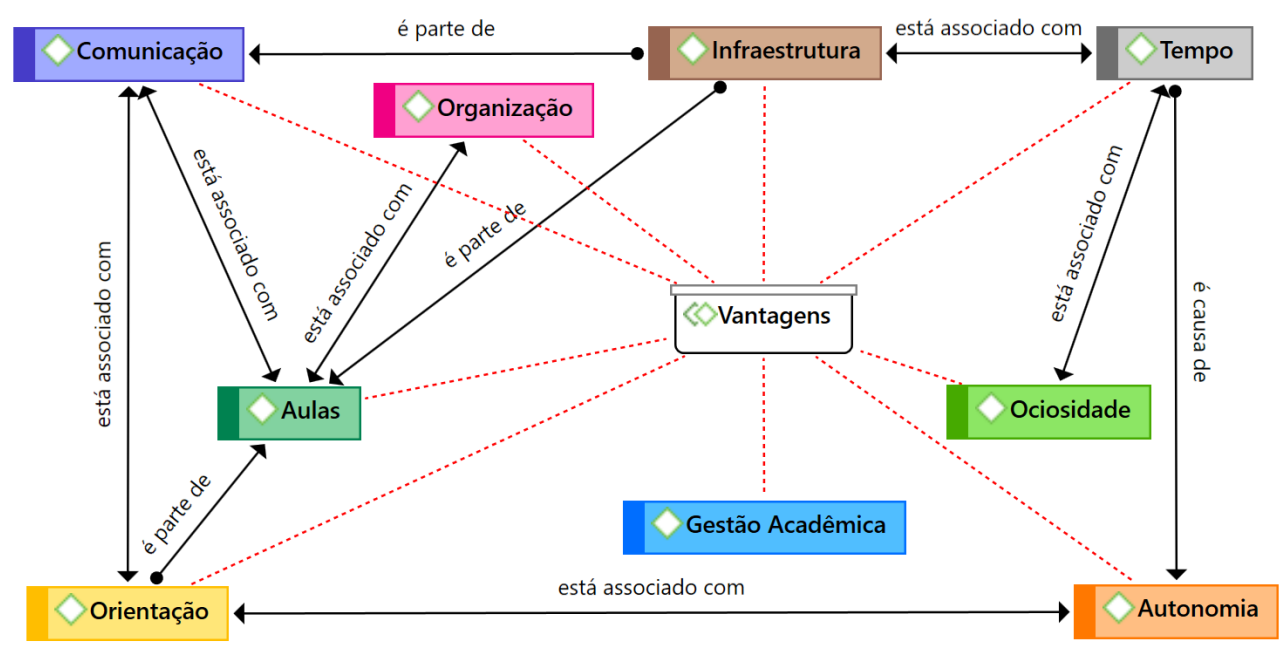

Figura 1. Categorias e relacionamentos identificados para as vantagens

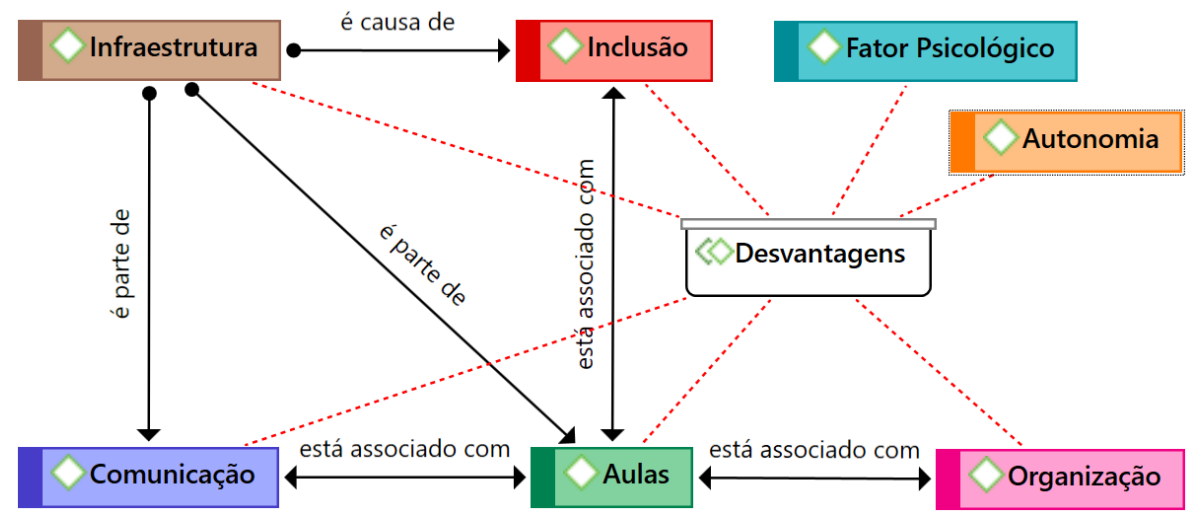

Figura 2. Categorias e relacionamentos identificados para as desvantagens

A Organização das atividades para uma aula remota eficaz também foi destacada, como no comentário de $\mathbf{P 2 1}$ em "Falta de uma cultura sobre a prática, falta de condições adequadas - acesso à internet, computadores, espaço para realização das atividades... Também considero que seja necessário um planejamento rigoroso das atividades a serem ministradas de forma remota".

A Orientação é um aspecto essencial no ensino, e algumas vezes foi citada em relação às aulas, como por $\mathbf{P 3 1}$ com "Flexibilidade de horário para interação com o curso, maior desenvolvimento de autonomia no processo de aprendizagem e força o professor a ser mais um orientador sobre os assuntos que são abordados do que um transmissor de conhecimento".

O Tempo quando bem gerenciado pode ter bons efeitos, como na citação de $\mathbf{P 8}$ em "... e ii) diminuição da ociosidade dos discentes, ocupando a mente dos mesmos" e na de $\mathbf{P 1}$ com "... aumento da autonomia de estudo do aluno, adequação do tempo de aulas/atividades as necessidades individuais ...”.

\subsection{Análises}

A infraestrutura adequada se apresenta como sendo uma condição básica para a participação dos alunos nas atividades remotas. Como relatado por $\mathbf{P 1 4} \mathrm{em}$ : "Nem todos 
IX Congresso Brasileiro de Informática na Educação (CBIE 2020)

Anais do XXXI Simpósio Brasileiro de Informática na Educação (SBIE 2020)

os alunos conseguem acessar a internet facilmente o que compromete a aprendizagem; os trabalhos em grupo são mais complexos e exige mais do que uma simples conexão com a internet, mas uma conexão remota entre todos os participantes que ainda não desenvolveram uma cultura para trabalhar de forma totalmente remota.". Pois, entende-se como infraestrutura a junção de equipamentos (dispositivos eletrônicos), serviços (internet), espaços (ambiente de estudo), materiais didáticos (livros, notas de aula, atividades etc.) dentre outros que possibilitem a inclusão do indivíduo no ambiente remoto.

É importante ressaltar como a infraestrutura impacta o acesso ao material didático, pois as diferentes realidades dos estudantes se apresentam em diferentes infraestruturas de acesso, evidenciando a existência de experiências de aprendizado bem diversas por fatores técnicos. Um exemplo é o relato de P24 a seguir: "A impossibilidade de garantir que o conteúdo e as experiências sejam distribuídas de modo equânime entre alunos."

A realidade socioeconômica dos alunos demonstra-se um fator de necessária consideração, pois enquanto o ambiente presencial a partir da estrutura da universidade possibilita livros, espaços de estudo, serviços e equipamentos para a comunidade acadêmica, o ambiente remoto vai solicitar do próprio aluno algumas dessas condições. P26 sugeriu o seguinte: "Alguns alunos relataram que não tem ambiente propício em casa para aulas. Moram em casas pequenas com muita gente. Então as atividades que tenho feito são opcionais.".

Em situações em que os alunos apresentam terem todas as condições necessárias para participar e o componente curricular, a disciplina, demonstra-se oportuna em um ambiente remoto, neste contexto, a solução se torna pertinente. Como apresentado por P11 com: "A possibilidade de manter, pelo menos parcialmente, a carga horária didática da disciplina de forma remota. No caso específico desta disciplina acho que se o aluno tiver o devido acesso aos recursos necessários, não haveria problema em ministrá-la integralmente à distância.". Entretanto, nem todas as disciplinas são estruturadas para ter a sua realização à distância, como ressaltado no comentário de P29: "Considerando que o aluno tenha acesso à Internet, materiais adequados, aptidão e ambiente propício, a desvantagem maior seria o desenvolvimento da parte prática da disciplina, tal como ela é estruturada no programa de disciplina.".

Materiais didáticos, como livros, notas de aula, listas de exercícios e outros são instrumentos importantes em uma aula, indubitavelmente, bastante importantes no processo de aprendizagem, servindo como uma forma de acesso ao conteúdo e também de complemento para as aulas. Contudo, no ambiente remoto é necessário uma reflexão acerca desses materiais, como apontado no comentário de P10: “i) os materiais didáticos da disciplina necessitariam de uma reformulação para serem ministrados como atividades remotas; e ii) mesmo que os materiais didáticos fossem reformulados, a conectividade com a Internet, a falta de softwares e recursos computacionais ainda seriam um problema para que todos tivessem a mesma oportunidade na disciplina.". O comentário ainda sugere uma relação entre a infraestrutura e os recursos didáticos.

Aulas remotas requerem que o professor se adapte a novas situações, estando apto para uma abordagem diferente da presencial. Enquanto presencialmente ele pode ser considerado um transmissor de conhecimento, a distância imposta pelo ambiente remoto solicita o desempenho de outros tipos de papéis como, por exemplo, um orientador, 
alguém que vai facilitar a aprendizagem como um guia. Um exemplo foi o comentário de P1 em: "Maior flexibilidade de horários e prazos, aumento da autonomia de estudo do aluno, adequação do tempo de aulas/atividades as necessidades individuais, valorização do professor como um facilitador do processo de estudo e aprendizagem (e não como alguém que vai transmitir o conhecimento)".

A troca de informações entre indivíduos em qualquer atividade social é de grande relevância. Portanto, para que a orientação do professor a seus alunos seja efetiva é fundamental uma constante comunicação, para reduzir o máximo possível de dúvidas e problemas acarretados por uma má intercomunicação, sugerido por $\mathbf{P 2 5}$ em: "É preciso uma interação mais efetiva com o discente, para o progresso na orientação. Além disso, o processo é bem mais rápido presencialmente e não exige recursos de conectividade para uma eventual videoconferência.".

É sempre importante que o emissor de uma mensagem obtenha um retorno. Em uma aula é sempre importante o professor ter feedback dos seus alunos e vice-versa. Então, a comunicação antes, durante e depois das aulas são essenciais, destacado por P26: "Eu estou ministrando remotamente atividades de programação. Os alunos me relataram que tem sido bom, uma oportunidade de conversar com outros e aprender algo novo.".

\section{Conclusão}

Em tempos de pandemia, atividades de ensino remotas acabam se tornando uma opção para que as atividades nas instituições de ensino continuem acontecendo. Porém, diversos fatores podem prejudicar esse esforço, como desmotivação, falta de experiência e infraestrutura inadequada. Este trabalho apresentou uma análise qualitativa sobre vantagens e desvantagens da aplicação de atividades remotas em disciplinas de um curso de graduação presencial no período de isolamento social. Como resultados principais, ressaltou-se que a infraestrutura é essencial para uma aula remota minimamente eficaz, para que possibilite a comunicação plena entre alunos e professores, e que os conteúdos e atividades possam ser bem executados por todos os participantes. Relatou-se também que a inclusão é uma preocupação de muitos professores, pois impacta diretamente no desempenho das aulas remotas. Ações para a inclusão digital dos alunos devem ser bem planejadas para que estes possam prosseguir sem muitos prejuízos no semestre letivo.

Este trabalho, como consequência, auxilia coordenadores e professores que desejam relatos de experiências sobre o ensino remoto, podendo se beneficiarem dos relatos de forma a previamente se adequarem às necessidades e a minimizar os problemas destacados, melhorando a didática e prática no ensino remoto em cursos de graduação com estruturas similares. Como trabalhos futuros, pretende-se ampliar essa pesquisa para um período pós-isolamento social, e analisar novamente as vantagens e desvantagens do ensino remoto. Além disso, identificar boas práticas que possam ser levadas para o ensino presencial. Este trabalho analisou o ponto de vista do docente. Assim, como um possível trabalho futuro, seria fazer uma pesquisa com ponto de vista do discente diante da sua experiência com atividades remotas. Com isso, discutir também quais foram as vantagens e desvantagens, na visão discente, diante das atividades remotas.

\section{Agradecimentos}

Este trabalho foi realizado com recursos do projeto NÚCLEO DE ANÁLISE QUALITATIVA PARA ESTUDOS DE COMPUTAÇÃO, EDITAL Nº 4/2019 - PREX, da 
IX Congresso Brasileiro de Informática na Educação (CBIE 2020)

Anais do XXXI Simpósio Brasileiro de Informática na Educação (SBIE 2020)

Universidade Federal do Ceará (UFC).

\section{Referências}

Cavalcanti, A., Dourado, R., Rodrigues, R., Alves, N., Silva, J., and Ramos, J. L. C. (2018). An analysis of self-regulated learning behavioral diversity in different scenarios in distance learning courses. In VII Congresso Brasileiro de Informática na Educação - XXIX Simpósio Brasileiro de Informática na Educação (SBIE 2019).

Corbin, J. and Strauss, A. (2014). Basics of Qualitative Research: Techniques and Procedures for Developing Grounded Theory. SAGE Publications, 4 edition.

DOU (2020). Portaria No. 343, DE 17 DE MARÇO DE 2020. Edição 53, Seção 1, p. 39. Disponível em: http://www.in.gov.br/en/web/dou/-/ portaria-n-343-de-17-de-marco-de-2020-248564376. Acesso em: 11 de julho de 2020.

Ferreira, T., Viana, D., Fernandes, J., and Santos, R. (2018). Identifying emerging topics and difficulties in software engineering education in brazil. In Proceedings of the XXXII Brazilian Symposium on Software Engineering, SBES '18, page 230-239, New York, NY, USA. Association for Computing Machinery.

Gil, A. C. (2008). Como elaborar projetos de pesquisa. Atlas, 4a. edition.

Gonçalves, E., Vilela, J., and Bezerra, J. (2018). Análise estatística de notas e interações em cursos a distância. In VII Congresso Brasileiro de Informática na Educação - XXIX Simpósio Brasileiro de Informática na Educação (SBIE 2019).

Jones, D. (1996). Computing by distance education: Problems and solutions. In Proceedings of the 1st Conference on Integrating Technology into Computer Science Education, ITiCSE '96, page 139-146, New York, NY, USA. Association for Computing Machinery.

Li, R., Pei, S., Chen, B., Song, Y., Zhang, T., Yang, W., and Shaman, J. (2020). Substantial undocumented infection facilitates the rapid dissemination of novel coronavirus (sarscov-2). Science, 368(6490):489-493.

Mogetti, R. S., Brod, F. A. T., and Lopes, J. L. B. (2020). Videoaula interativa como material potencialmente significativo na educação a distância. RENOTE - Revista Novas Tecnologias na Educação, 18(1).

Moreira Neto, M., Coutinho, E. F., and Moreira, L. O. (2020). Reflexões sobre os Aspectos Sociais da Tecnologia Blockchain na Pandemia do SARS-CoV2. Revista Sistemas e Mídias Digitais (RSMD), 5(1).

Santos, C., Coutinho, E. F., Paillard, G. A. L., and Moreira, L. O. (2020). Um relato sobre os desafios das atividades remotas em um curso de graduação presencial diante das medidas de prevenção contra o SARS-CoV-2. Revista Novas Tecnologias na Educação (RENOTE), 18(1).

Silva Junior, L. C. F., Ferreira, A. R., Pimental, F. S. C., Lima, W. M., and Assunção, I. P. (2020). Atividades na pós-graduação utilizando ferramentas digitais no contexto da crise da covid 19: Análise qualitativa descritiva. Revista de Educação a Distância (EmRede), 7(1):276-293. 